\title{
Ultrastructural study of non-traumatic recurrent corneal erosion
}

\author{
R. G. TRIPATHI AND A. J. BRON \\ Departments of Pathology and Clinical Ophthalmology, Institute of Ophthalmology, University of \\ London
}

The recurrent epithelial erosion syndrome of the cornea is a common disorder; it usually follows specific trauma to the cornea, though it may present without such a history. It may sometimes be inherited or may occur in association with inherited corneal dystrophies (Duke-Elder and Leigh, 1965; Griffith and Fine, 1967). Clinically, the patient presents with symptoms of a sharp pain on opening the eyes in the morning followed by watering, photophobia, and a variable degree of blurring of vision. Cystic changes within the epithelium are recognized biomicroscopical features. This may be associated with a slight lifting, linear cracks, or frank loss of epithelium which gives the condition its name. Our? knowledge of the aetiopathogenesis of this disorder is, however, limited. In cases precipitated by trauma, it has been suggested that the basement membrane over the traumatized area of the cornea is defective (Goldman, Dohlman, and Kravitt, I969; Khodadoust, Silverstein, Kenyon, and Dowling, 1968). The purpose of this paper is to report for the first time the ultrastructural features of epithelial biopsies taken from a case of bilateral recurrent erosion syndrome of non-traumatic origin.

\section{Glinical report}

AN UNMARRIED White FEMALE AGED 29 YeARS presented in June, I969, with a history of intermittent irritation and watering of the right eye for some weeks. The symptoms resolved on treatment with padding and chloramphenicol ointment. The visual acuity was right $6 / 12$ and left $6 / 9$ uncorrected.

In September, I969, both corneae exhibited epithelial cysts, sub-axial in location (Fig. I, overleaf). Over the next 4 months the patient suffered episodes of right ocular pain followed by watering and soreness. Some episodes occurred on waking.

In January, 1970, a left diagnostic epithelial biopsy was performed including the area of the cysts. Healing was slow but was complete by the fifth postoperative day. The left eye was asymptomatic 3 weeks postoperatively but showed some very fine cystic changes in the epithelium. The right eye continued to be occasionally symptomatic, with pain on waking.

In May, 1970, a right epithelial biopsy was performed. At this time cysts had reappeared in the left cornea in approximately the same position as they had occupied in October, 1969. The right eye healed uneventfully and 2 weeks postoperatively the corneal epithelium was entirely free of cysts and the eye was comfortable. 

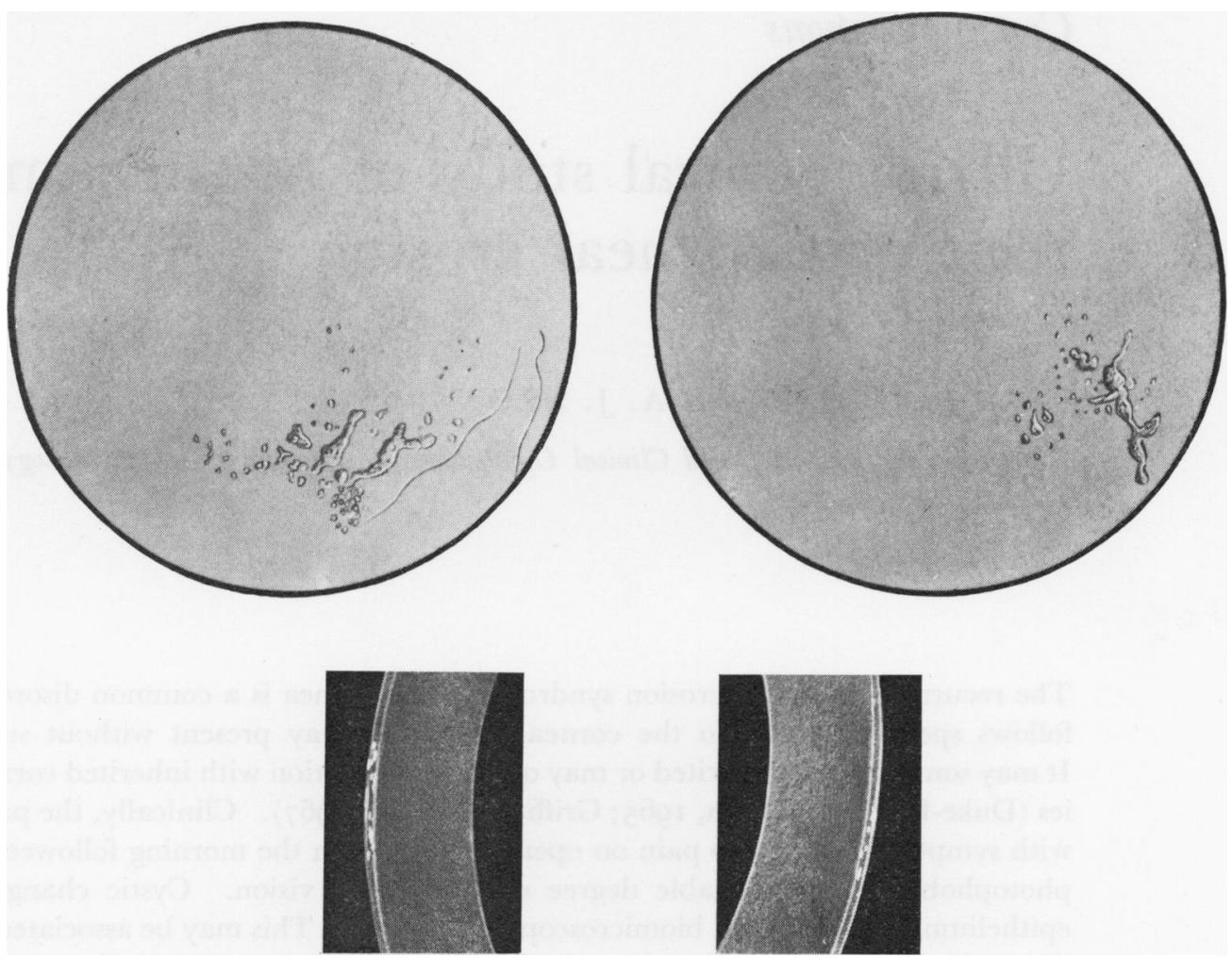

FIG. I Painting of correae, showing the clinical appearance of epithelial cysts

This encouraging response was short-lived, however, for I I days after the right biopsy the patient presented again with symptoms of a painful watering left eye. The signs were typical of a recurrent erosion, the lower epithelium being oedematous and lifted, and containing semiopaque cysts and plaques. It also showed an irregular breach. In the right eye at this time the epithelial cysts had reappeared, though they now occupied a ring-shaped zone of the cornea.

After the healing of the left erosion, both eyes have remained fairly comfortable, but the cysts have persisted. Throughout the period of observation, both before and after biopsy, the cysts were seen to vary in number and arrangement but not in the general position occupied in the cornea.

No history of trauma was elicited from the patient and she was not taking the contraceptive pill; nor was there any family history of eye disease. In her past history, she was said to have had a "spotty retina" in childhood but the nature of this was not known. On general ocular examination there was a mild intermittent rotary nystagmus, ocular tensions were normal, the media were clear, and the discs and maculae were normal. The retinae showed slight brownish pigmentary changes. Electrodiagnostic tests were normal.

\section{Materials and methods}

Corneal specimens from the right and left eyes of the patient were obtained on separate occasions under general anaesthesia. The epithelium was kept moist during the operation by frequent irrigation with physiological saline. An area of the epithelium $5 \times 5 \mathrm{~mm}$. was carefully stripped from the surface of the cornea.

Each specimen was divided into two halves; one half was fixed in to per cent. formol saline for conventional light microscopy and the other half in chilled isotonic osmium tetroxide at $\mathrm{pH} 7 \cdot 4$ 
for electron microscopy. The tissue fixed in formol saline was embedded in paraffin wax and sections were stained with haematoxylin and eosin, silver stain for reticulin, and periodic acidSchiff (PAS) reaction. The osmium-fixed tissue was embedded in Araldite and sections were cut on a LKB ultramicrotome using glass knives. Thick sections ( $\mathrm{I} \mu \mathrm{m}$.) for light microscopy were stained with toluidine blue and thin sections $(50-90 \mathrm{~nm}$.) for electron microscopy were stained with uranyl acetate and lead citrate. Electron micrographs were taken with an AEI EM6 electron microscope.

\section{Results}

\section{LIGHT MICROSCOPY}

Histological examination of the epithelial specimens showed virtually identical changes in both Araldite and paraffin wax preparations.

Sections showed a full-thickness corneal epithelium and subepithelial basement membrane (Fig. 2). The epithelium was nearly twice as thick as normal mainly because of a variable degree of inter- and intra-cellular oedema, more marked in some places than others. The cells were somewhat irregular in size and arrangement, but the normal architecture of the epithelium was generally maintained. Examination of both unstained and stained sections (paraffin wax and Araldite) showed the majority of the epithelial cells to be fairly uniform in cellular density and staining reaction. Isolated or small groups of epithelial cells in the basal layer and occasionally in the middle and superficial layers were, however, swollen in appearance and had low cellular density; they also

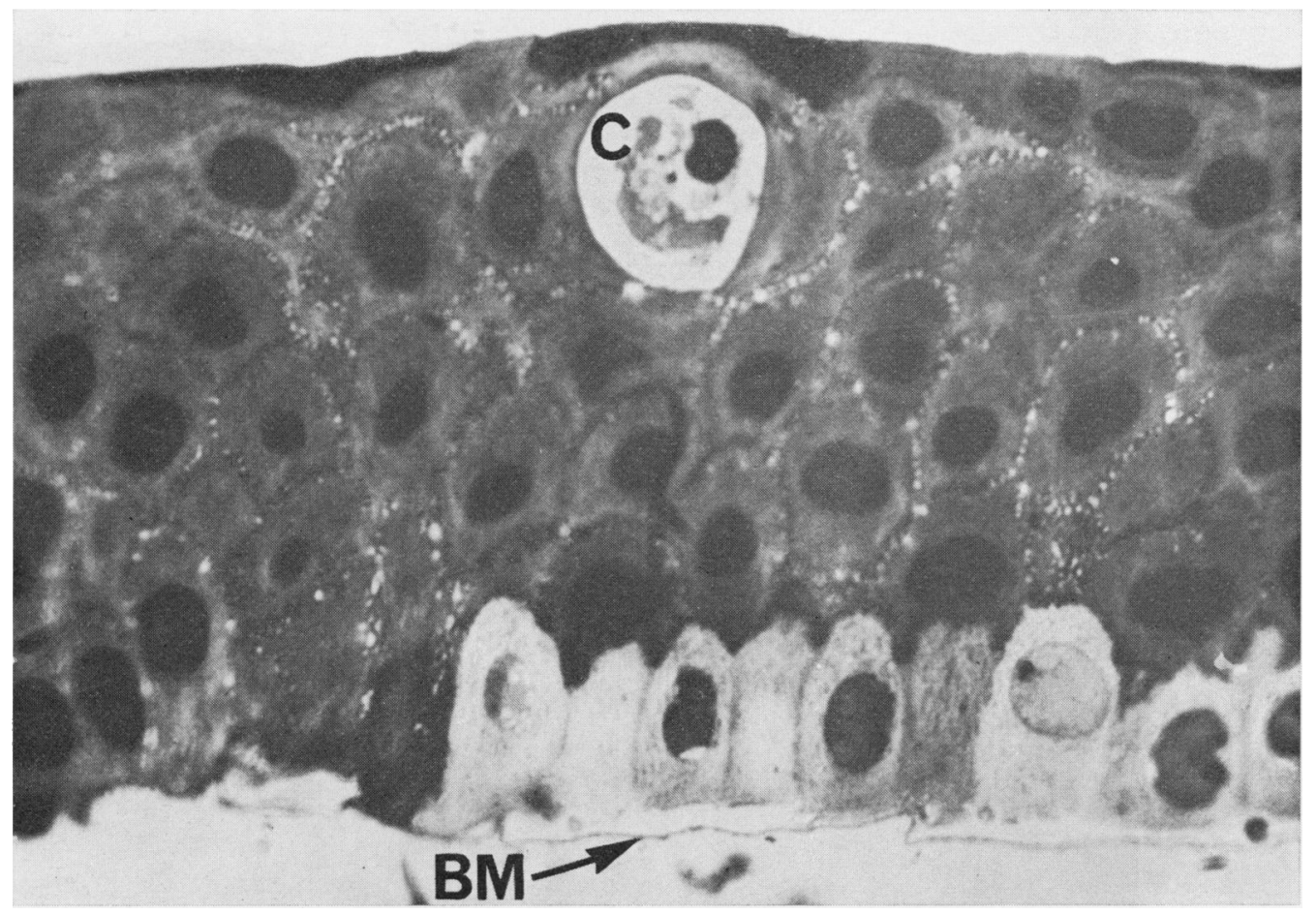

FIG. 2 Light photomicrograph of corneal epithelium showing "pale" cells in basal zone with loosely attached basement membrane $(B M)$, widespread intercellular oedema, and an intraepithelial location of a cyst $(C)$ containing cellular debris. Araldite embedded, toluidine blue stained. $\quad \times 1,150$ 
reacted poorly with the stains employed. The nuclei of these "pale" cells showed vacuoles, nuclear blebs, a coarsely granular chromatin, and poor basophilia; the cytoplasm often showed small vacuoles, a poorly-defined cell membrane, and only faint eosinophilia. Occasionally the epithelium was infiltrated with isolated non-epithelial cells (leucocytes). There was, however, no evidence of inflammation, ulceration, scarring, or vascularisation throughout the epithelial specimens.

There were discrete intraepithelial cysts (Figs 2 and 3) mostly located in the superficial one-third of the epithelium; some of the cysts opened on to the anterior surface. In many places, the anterior surface of the epithelium was rough and uneven mainly because of erupted cysts and exfoliation of the superficial epithelial cells. The intraepithelial cysts were typically ovoid or round in shape and ranged from 1o to 100 $\mu \mathrm{m}$. in size. The edges of the cysts were generally smooth. Smaller cysts were usually surrounded by a single epithelial cell which in turn was surrounded by one to three successive layers of flattened epithelial cells in an onion-skin fashion (Fig. 3). Most cysts contained a debris-like substance which was moderately PAS-positive. Some cysts, however, contained dense granules and pyknotic nuclei. The size and distribution of the cysts corresponded to the cysts seen clinically in the corneal epithelium of both eyes of the patient.

The subepithelial basement membrane found beneath the basal cell layer was strongly PAS-positive. In most places this membrane was completely intact and closely applied to the basal aspect of the basal cell layer. In the region of poorly-staining cells, however, this membrane was loosely attached or even partly separated (Fig. 2).

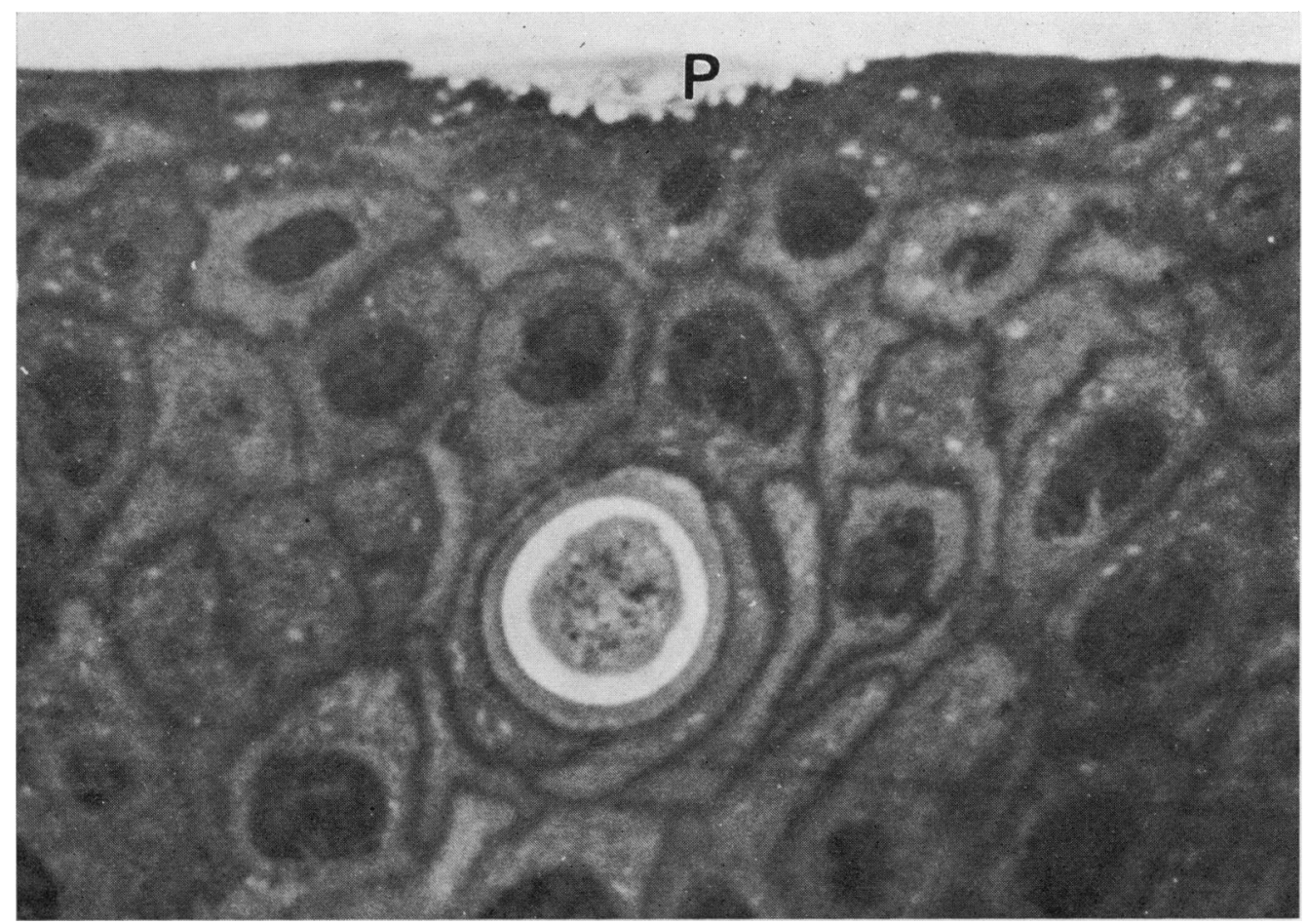

FIG. 3 Intraepithelial cyst containing cellular debris and surrounded by fattened epithelial cells in an onionskin fashion. $P=A$ "pale" cell in the superficial region of the epithelium. Light photomicrograph. Araldite embedded, toluidine blue stained. $\quad \times 1,620$ 


\section{ELECTRON MICROSCOPY}

The majority of the epithelial cells, which stained well and uniformly in light microscopical preparations, reacted similarly to the heavy metal stains of electron microscopy (i.e. uranyl acetate and lead citrate). The desmosomal attachments of these cells were prominent, but in many places the interdigitating cell borders were separated by intervening electron optically empty clefts (Fig. 4, overleaf). Some clefts, however, contained a flocculent material probably derived from protein elements of oedematous fluid. The cell cytoplasm contained numerous rough surface endoplasmic reticulum, Golgi apparatus, and glycogen granules. Mitochondria were generally small and scanty, and in some cells of the superficial layer, many of them were swollen. The cells were rich in tonofilaments which partly obscured the details of the intracellular organelles and, in conjunction with the cytoplasmic matrix, were obviously responsible for the cellular density. Each cell contained a nucleus which was orientated in the long axis of the cell and was enclosed by a prominent inner nuclear membrane and a poorly-defined outer nuclear membrane. The nuclear outline was irregular and undulating and the chromatin was finely granular and uniformly distributed throughout the nucleus.

Electron microscopy confirmed the low cellular density and predominant basal location of the "pale" cells seen by light microscopy (Fig. 5, overleaf). The desmosomal attachments of these cells were less dense and the adjacent cells of the same group showed fewer interdigitations and intercellular clefts. The cell membrane was poorly demarcated and occasionally interrupted in places. The cytoplasm generally contained a reduced number of tonofibrils of low electron density. The cytoplasmic matrix was similarly reduced in electron density, hence the "pale" appearance of these cells. Among the intracellular organelles (Fig. 6), the endoplasmic reticulum showed varying degrees of segmental dilatation and marked cystic changes. The mitochondria were generally swollen and many were cystic. Lysosomal bodies were larger in size although not unduly increasedin number. In places the outer nuclear membrane was widely separated from the inner nuclear membrane, thus producing nuclear blebs. The chromatin content of the nucleus was coarsely granular and showed clumping, giving a mottled electron dense appearance.

The cysts were lined by the plasma membrane of the adjacent epithelial cells. Smaller cysts in isolated thin sections were contained by a single epithelial cell which often showed preservation of the interdigitated wavy pattern of the cell membrane (Figs 7 and 8). The plasma membrane of the epithelial cells encircling the larger cysts was usually smooth. The lining epithelial cells of some cysts, however, were degenerate (Fig. 9). The peripheral zone of unerupted microcysts was generally electron optically empty (Figs 7, 8, and 9). The central zone was occupied by cellular components varying from a recognizable epithelial cell with its nuclear and cytoplasmic organelles and a wavy interdigitated pattern of the cell membrane (Fig. 7), to a cellular debris consisting of granulo-amorphous and fibrous elements in which degenerate cell organelles could only occasionally be recognised (Figs 8 and 9). Some cysts had opened to the surface of the cornea and emptied out their contents.

The subepithelial basement membrane (Figs 4 and 5) was moderately electron dense and varied in thickness from 50 to $100 \mathrm{~nm}$. It consisted of amorphous and finely fibrillar elements. The attachment between the basement membrane and the basal cells was mediated by hemidesmosomes which were, however, markedly reduced or even absent in the area of "pale" basal cells; consequently, the basement membrane was loosely attached or even completely separated (Fig. 5). Occasionally, a granular material intervened between the basement membrane and some "pale" basal cells (Fig. 5). 


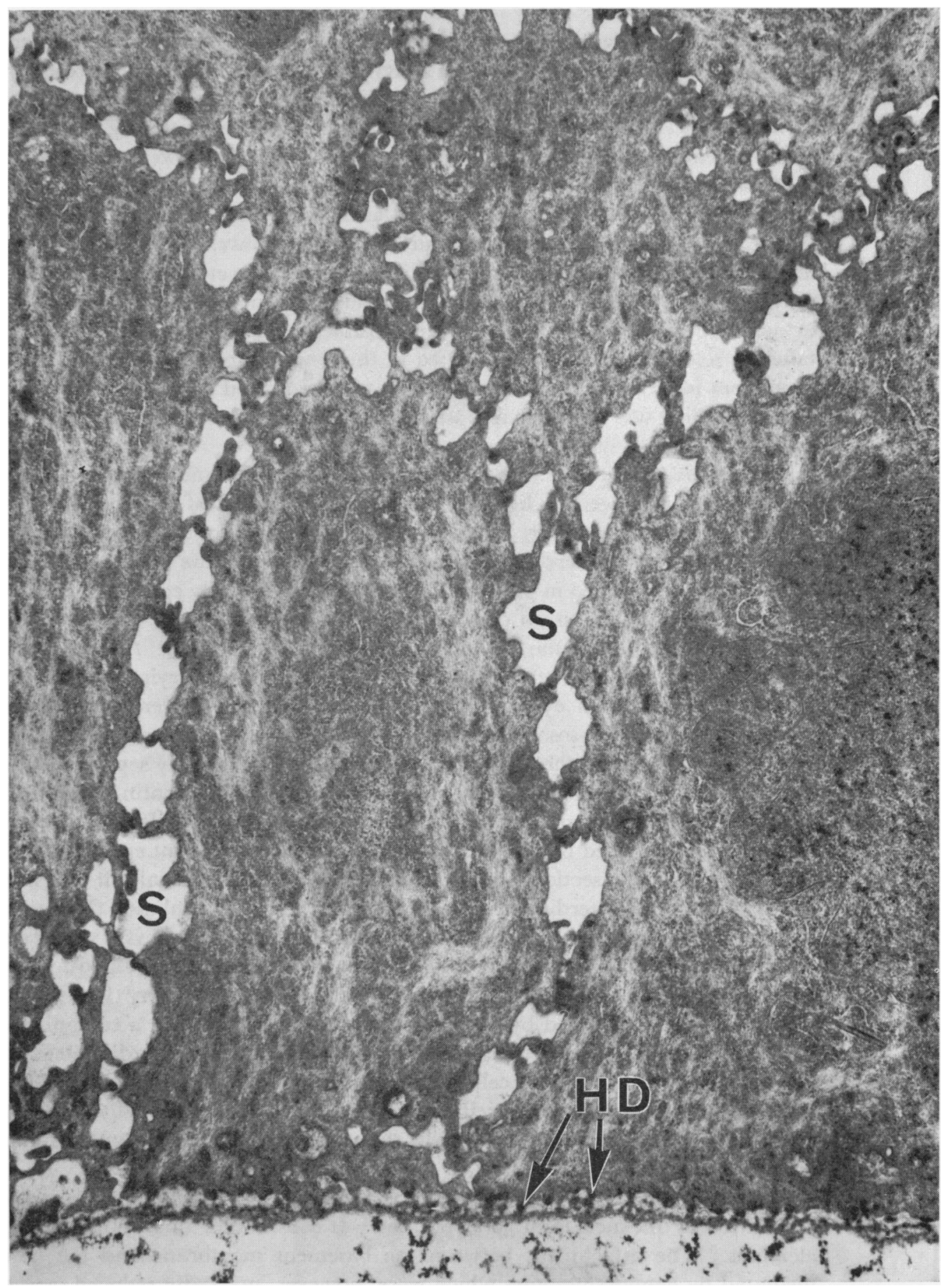

FIG. 4 Electron micrograph of corneal epithelium showing attachments of basal cells to basement membrane mediated by hemidesomosomes $(H D)$ and widening of intercellular spaces $(S)$ through fluid accumulation. The intracellular content is relatively normal. Uranyl acetate and lead citrate stained. $\times$ I I,000 


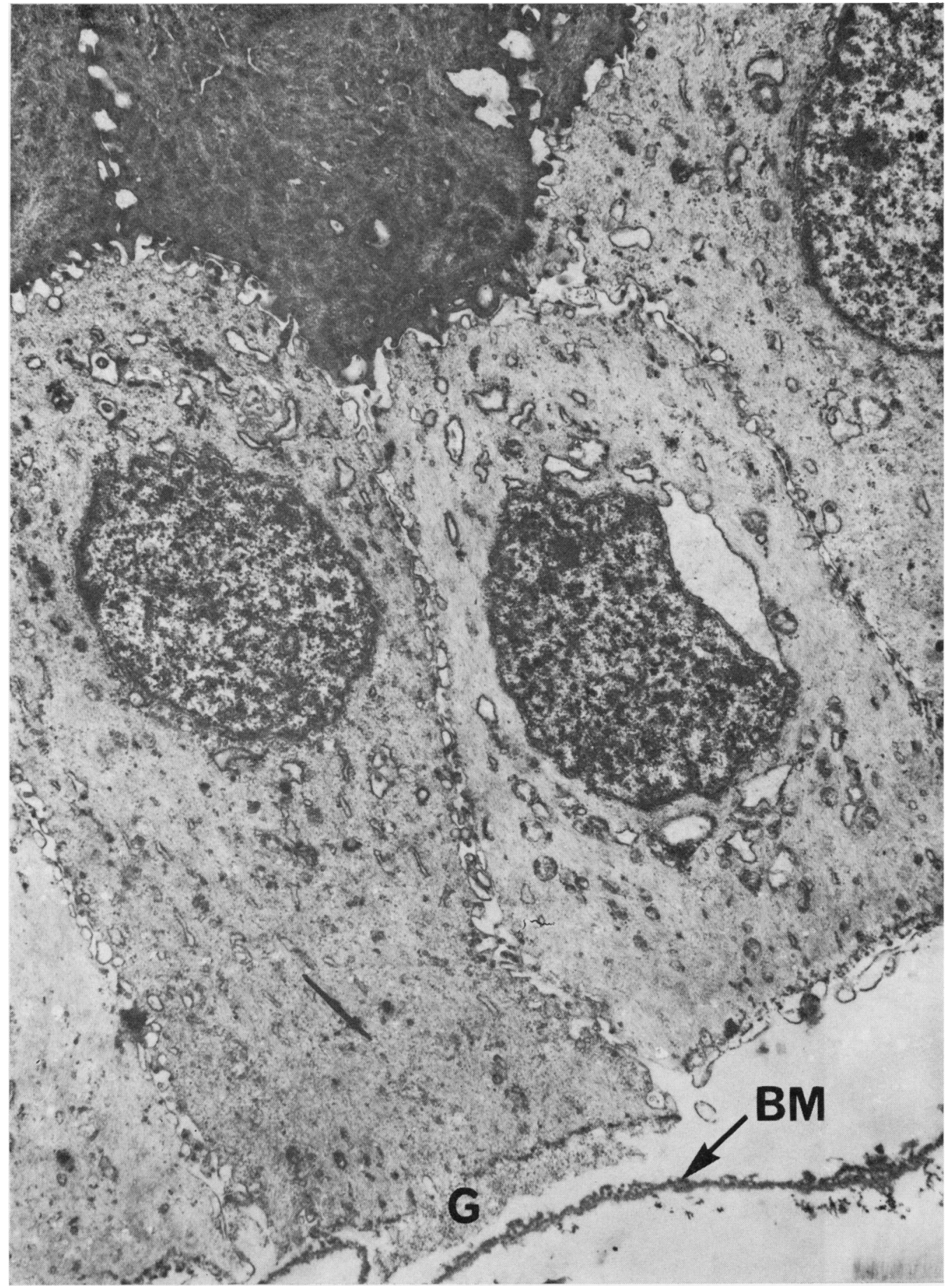

FIG. 5 Electron micrograph of corneal epithelium showing a detached basement membrane (BM) with almost complete absence of hemidesmosomes in the region of "pale" cells. Note poorly demarcated and interrupted cell membrane, nuclear bleb, and granular chromatin of these cells. $G=$ Granular material between the "pale" basal cells and basement membrane. Uranyl acetate and lead citrate stained. $\times 10,000$ 


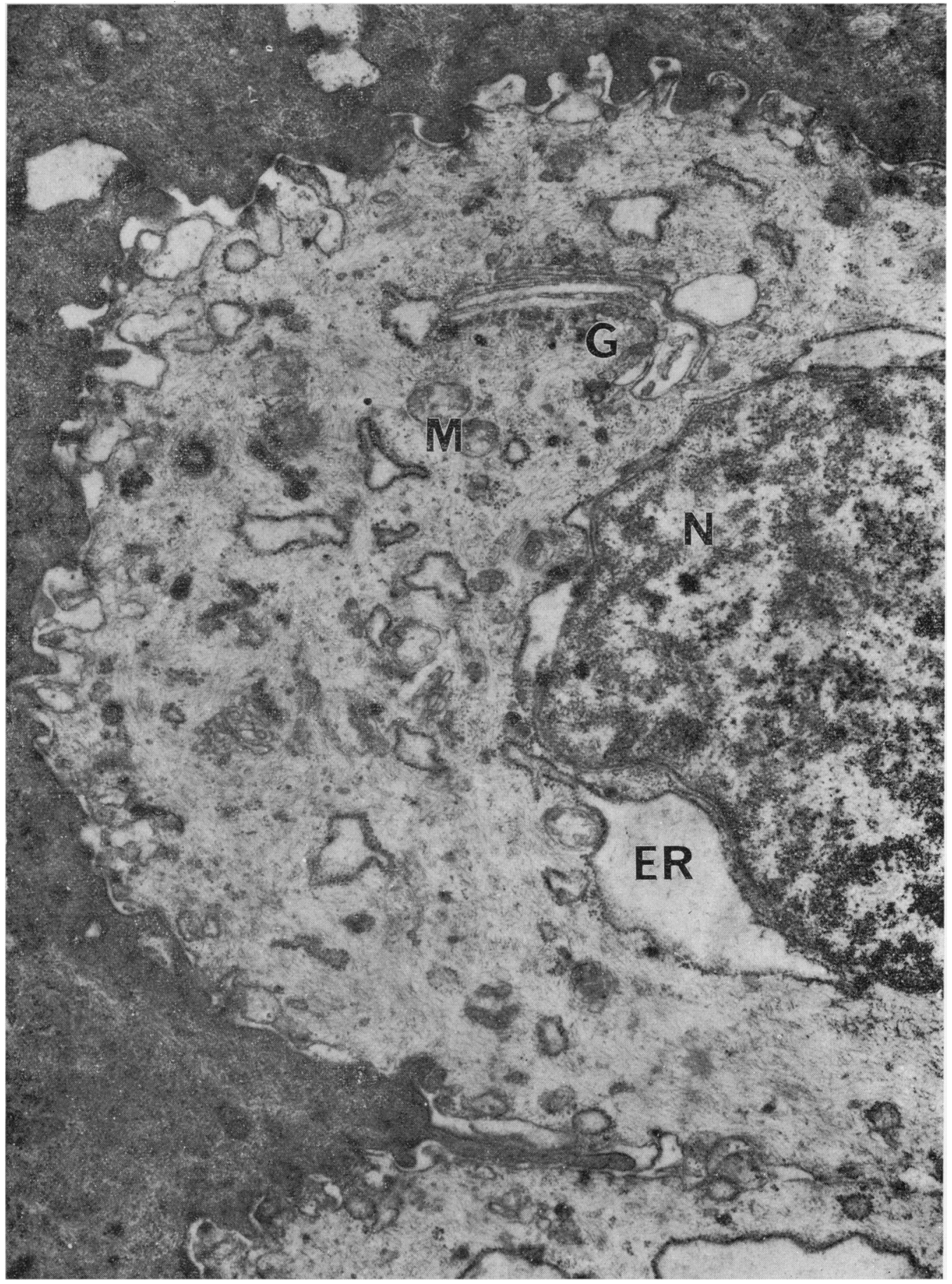

FIG. 6 Degenerative changes in "pale" cells are apparent from clumping in chromatin granules and nuclear blebs in nucleus $(\mathcal{N})$, dilated cisternae of endoplasmic reticulum $(E R)$ and Golgi apparatus $(G)$, cystic mitochondria $(M)$, and decreased electron density of the tonofilaments and cytoplasmic matrix. The surrounding epithelium shows normal cell density. Electron micrograph. Uranyl acetate and lead citrate stained. $\quad \times 16,650$ 


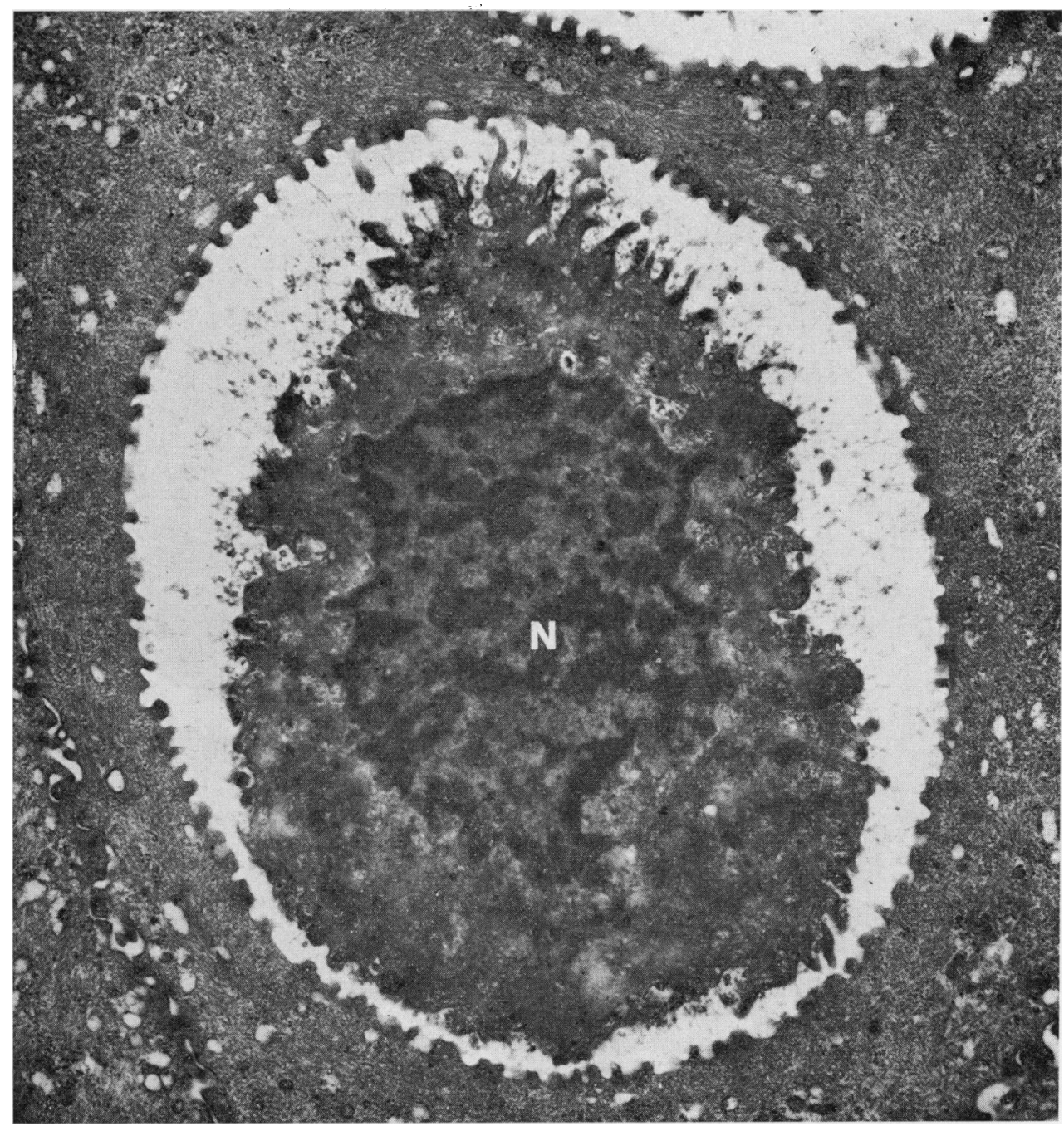

FIG. 7 Intraepithelial cyst containing degenerating epithelial cell. Note also separation of cell interdigitations and normal intracellular content of surrounding epithelial cell. $\mathcal{N}=\mathcal{N}$ ucleus. Electron micrograph. Uranyl acetate and lead citrate. $\times 25,000$

\section{Discussion}

The morphological features of the "pale" cells observed in the present case are interpreted as being due to intracellular oedema, and indeed a similar conclusion has been reached by other authors (Hogan and Zimmerman, I962; Duke-Elder and Leigh, I965; Goldman and Kuwabara, 1969; Iwamoto and DeVoe, 1971). It is significant to note that, except for the areas where the "pale" basal cells were present, the morphology and the attachments of the basal cells to the basement membrane were relatively normal. The almost complete absence of hemidesmosomes in the region of "pale" basal cells could provide a structural basis for the separation and resulting loss of the epithelium seen clinically; however, the precise mode of epithelial separation remains obscure. It is possible, 


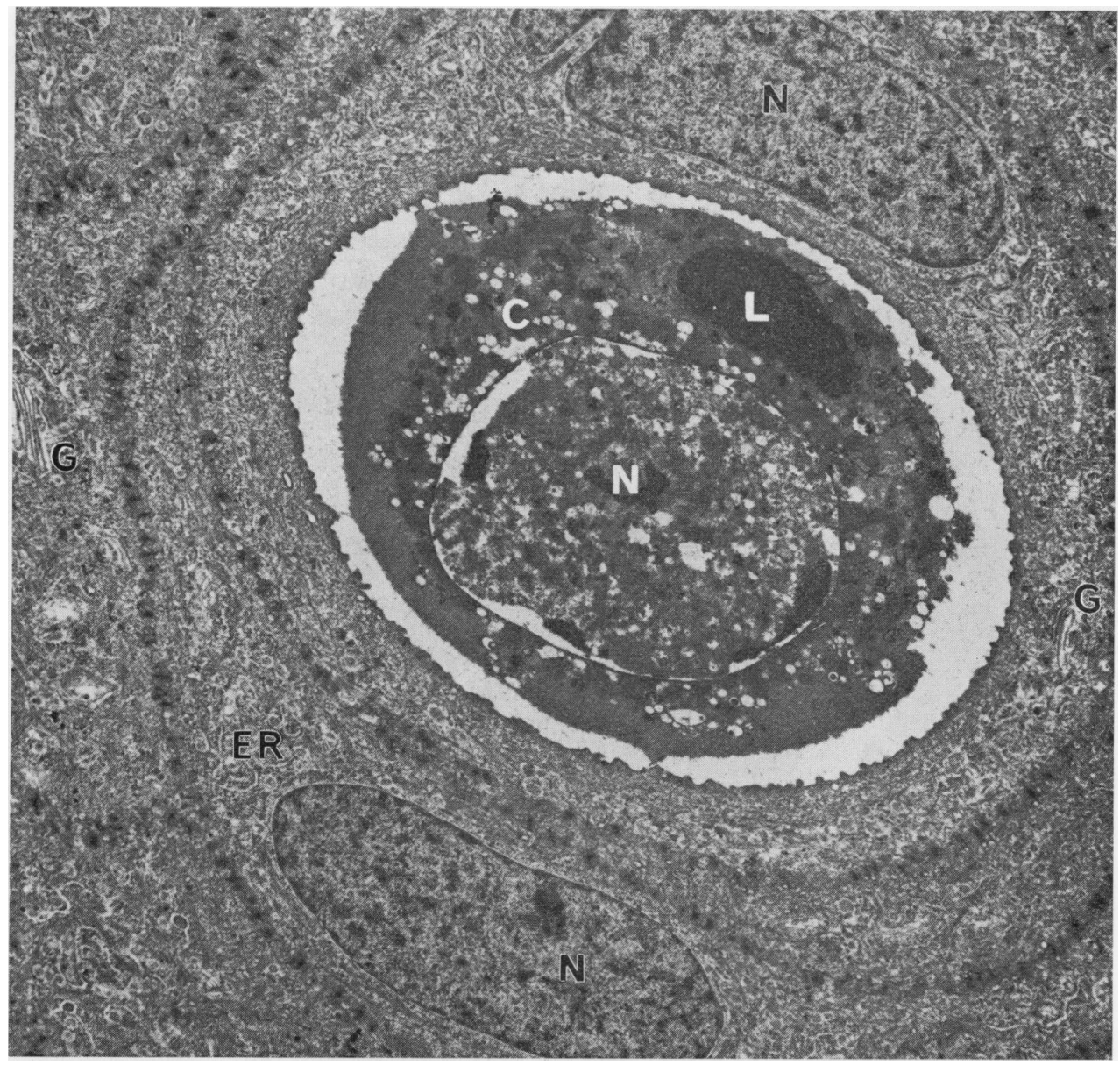

FIG. 8 Intraepithelial cyst containing degenerating epithelial cell; the nucleus $(\mathcal{N})$ is pyknotic and the granular cytoplasm $(C)$ contains lipid $(L)$. Note concentric arrangement of surrounding epithelial cells having a normal intracellular content. $\mathcal{N}=$ Nucleus. $E R=$ Endoplasmic reticulum. $G=$ Golgi apparatus. Electron micrograph. Uranyl acetate and lead citrate stained. $\quad \times 6,650$

as Cogan (194I) suggested, that the hypotonicity of the tear film in the morning, owing to the lack of evaporation during sleeping hours, combined with the absence of tight epithelial adhesion, may result in fluid accumulation between the epithelium and stroma. The question remains, however, whether the absence of hemidesmosomes occurs as a result of oedema or is due to an inherent defect in some basal cells.

In an experimental study on the adhesion of regenerating corneal epithelium in rabbits, Khodadoust and others (1968) have suggested that recurrent corneal erosion may be due to a defect in the basement membrane, either through failure of its production or through defective adhesion to Bowman's zone. To some extent, the latter nature of the defect is apparent in our case, since in stripping the epithelium, the basement membrane remained attached to the basal epithelium, whereas it is normally left behind.

Whether this alteration was due to a change in the constitution and behaviour of the base, ment membrane or was simply a manifestation of existing epithelial oedema (TripathiI972) is not known. 


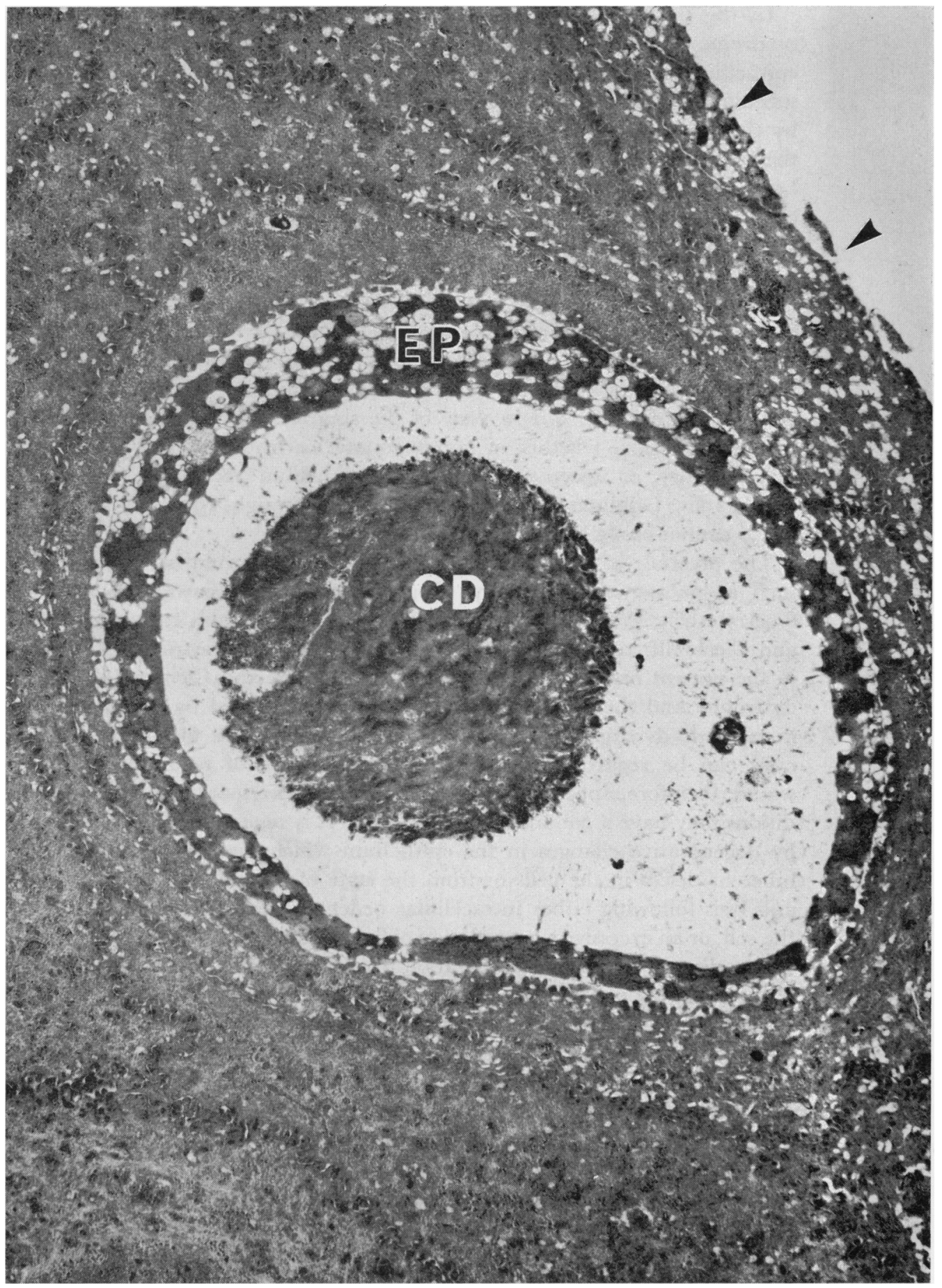

FIG. 9 Intraepithelial cyst containing cellular debris $(C D)$. Note also surrounding epithelial cell (EP) showing degenerative changes. Arrow denotes superficial cells of epithelium. Electron micrograph. Uranyl acetate and lead citrate stained. $\quad \times 1 \mathrm{I}, 000$ 
In the first and only reported ultrastructural study of traumatic recurrent erosion syndrome, Goldman and others (1969) have suggested that the poor adhesiveness of epithelium is related to a defect in the basement membrane. Although we are unable to substantiate this hypothesis, certain findings of the present case are similar to those reported by these authors, such as the absence of attachment bodies (hemidesmosomes) between the basement membrane and basal cells of some regions, degenerative changes in some basal cells and the presence of inter- and intra-cellular oedema. The similarity of these changes would seem to suggest a common pathogenesis for both the traumatic and nontraumatic recurrent erosion. The role of trauma in some cases may, therefore, be secondary, as already suggested by Duke-Elder and Leigh (1965). Indeed, the virtually identical bilateral clinicopathological features of this case and the absence of inflammatory reaction and infective agents (viral and bacterial) would favour a metabolic and/or dystrophic basis for its aetiology. The extent to which the alterations in osmotic properties and chemical constituents of the tear fluid are responsible for the sequence of events can only be conjectured; but in view of the similarity of the clinicopathological picture of recurrent erosion, whether of non-traumatic or traumatic origin (i.e. after mechanical, inflammatory, or infective insult of the epithelium: Kaufman, r964; Duke-Elder and Leigh, 1965; Goldman and others, I969; Roseborough, 1970), the role of such a common factor cannot easily be disregarded.

The presence of intraepithelial cysts has been reported in various epithelial disorders such as microcystic dystrophy (Cogan, Donaldson, Kuwabara, and Marshall, 1964; Guerry, I965; Wolter and Fralick, I966) and Meesmann's corneal dystrophy (Kuwabara and Ciccarelli, I964; Burns, I968). In view of the ultrastructural similarity of the cysts in the present case to that reported by Kuwabara and Giccarelli (r964) in Meesmann's dystrophy and the structural similarity to that reported by Cogan and others (1964) in microcystic dystrophy, it does not seem likely that the formation of the intraepithelial cysts can be regarded as a unique manifestation of recurrent erosion syndrome. It would, therefore, appear that the epithelial cysts originating in these and other allied conditions may have a common pathogenesis. It is suggested that the microcysts are formed by degenerative changes in the epithelium which may result either from a primary or inherent defect in the cells or from the state of epithelial oedema (i.e. cell degeneration and lysis following either intracellular oedema, the fluid eventually being released from the cell, or an excessive accumulation of fluid in the intercellular spaces around an epithelial cell leading to its complete separation from the surrounding cells). Further enlargement of the cyst may occur because of the absorption of fluid from the surrounding epithelium (through osmotic and ionic imbalance created by the cyst) and also by the involvement of the encircling epithelial cells. Larger cysts are formed by the involvement of a group of epithelial cells. We further believe that the concentric, flattened arrangement of the epithelial cells surrounding the cyst in an onion-skin fashion results from the invagination of the expanding cyst into the neighbouring cells. To what extent a protective stimulus is responsible for this "encapsulated" appearance of the cyst is not known. From the examination of many sections, however, the impression is gained that the characteristic encirclement of the cyst by the adjacent epithelial cells is related to its level of origin, to its size, and possibly to the rate of eruption. Smaller cysts may even be engulfed by a single epithelial cell, not unlike the engulfment of keratinized cells by non-keratinized epithelial cells seen in Bowen's disease (Tripathi and Garner, 1972). All cysts eventually evacuate their contents on the surface of the cornea, which may be responsible for the punctate staining seen clinically in intact epithelium in addition to that shown by the intact cysts. 


\section{Summary}

The ultrastructural study of epithelial biopsies taken from a case of recurrent epithelial erosion syndrome of non-traumatic origin suggests that the predominance of "pale" cells in the basal layer results from intracellular oedema. This, together with the absence of hemidesmosomes and a separation of basement membrane, provides a structural basis for the epithelial erosion. The degeneration and lysis of the epithelial cells (depending on their size and surroundings) account for the characteristic cyst formation. The morphogenesis of the cysts is discussed and their morphology is compared with similar cysts in other epithelial disorders. There was no evidence of inflammation or the presence of infective agents. The aetiological factors responsible for the pathogenesis of this disease remain obscure; but consideration has been given to a dystrophic diasthesis of the corneal epithelium and to the role of hypothetical alterations in the constituents of the tear fluid.

It is a pleasure to record the helpful comments of Professor Norman Ashton, F.R.S., during the preparation of this paper.

\section{References}

BURns, R. P. (1968) Trans. Amer. ophthal. Soc., 66, 53 I

COGAN, D. G. (I94I) Arch. Ophthal. (Chicago), 25, $94 \mathrm{I}$

, Donaldson, D. D., kuwabara, T., and marshall, D. (1964) Trans. Amer. ophthal. Soc., 62, 213

DUKE-ELDER, S., and LEIGH, A. G. (1965) "System of Ophthalmology", vol. 8, pt 2. Kimpton,

London

goldman, J. N., Dohlman, c. H., and kravitt, B. A. (i969) Trans. Amer. Acad. Ophthal. Otolaryngol.,

$73,47 \mathrm{I}$

and kuwabara, т. (I968) "Histopathology of corneal edema", in "Corneal Edema",

ed. C. H. Dohlman. Int. Ophthal. Clin., 8, no 3, p. 56r. Little, Brown, Boston

GRIFFITH, D. G., and FINE, B. s. (1967) Amer. 7. Ophthal., 63, 1659

Guerrv, D. (1965) Trans. Amer. Ophthal. Soc., 63, 320

hogan, м. J., and zimmerman, L. E. (I962) "Ophthalmic Pathology", p. 3ir. Saunders,

Philadelphia

iWAmoto, т., and Devoe, A. G. (197 I) Invest. Ophthal., I0, 29

kaufman, h. E. (1964) Amer. F. Ophthal., 57, 983

KHODAdOUSt, A. A., Silverstein, A. M., Kenyon, K. R., and doWling, J. E. (I968) Ibid., 65, 339

kUWABara, T., and ciccarelli, E. c. (1964) Arch. Ophthal., (Chicago), 71, 676

roseborough, G. F. (1970) Canad. F. Ophthal., 5, $34^{8}$

TRIPATHI, R. C. (1972) "Ultrastructure of the normal human cornea", in "Corneal Grafting",

ed. T. A. Casey. Butterworths, London (In press)

and GARNer, A. (1972) Cancer Res. (In press)

WOlter, J. R., and FRALICK, F. B. (ig66) Arch. Ophthal. (Chicago), 75, 380 